\title{
Retos y dificultades para la implantación de la adopción abierta en España. El papel de la mediación
}

\author{
Rosser Limiñana, Ana ${ }^{1}$; Berástegui Pedro-viejo, Ana $^{2}$
}

Recibido: 12 de septiembre de 2017 / Aceptado: 23 de octubre de 2017

Resumen. Las últimas modificaciones producidas en la normativa española sobre protección a la infancia y la adolescencia incorporan la figura de la adopción abierta. Se trata de una medida innovadora ya que choca con la ruptura del vínculo entre el menor y su familia biológica que suponía hasta entonces la adopción y permite al adoptado mantener relación con su familia de origen a través de vistas o comunicaciones. Si bien la adopción abierta cuenta con una larga tradición en otros países, su implantación en España suscita importantes interrogantes.

El objetivo de este trabajo es el estudio de las opiniones de expertos sobre las condiciones para su implantación en España mediante el análisis de contenido temático de las entrevistas realizadas.

Del análisis se desprenden los retos y dificultades de su implantación y la importancia de recurrir a la mediación como estrategia para promover los contactos.

Palabras clave: Adopción; adopción abierta; mediación; España; análisis de contenido.

\section{[en] Challenges and difficulties for the implementation of open adoption in Spain. The role of mediation}

\begin{abstract}
The latest changes made in the Spanish legislation on protection of children and adolescents incorporate the figure of open adoption. This is an innovative measure because it clashes with the obligation to break the link between the child and his biological family contemplated until then in the adoption and allows the adoptee to maintain relationship with his family of origin through views or communications. Although open adoption has a long tradition in other countries, its implementation in Spain raises important questions.

The objective of this work is the study of expert opinions on the conditions for its implementation in Spain through the analysis of the thematic content of the interviews carried out.

This analysis highlight the challenges and difficulties of its implementation, as well as the importance of mediation as a strategy for promoting contacts.
\end{abstract}

Keywords: Adoption; open adoption; mediation; Spain; content analysis.

Sumario. 1. Introducción. 2. Método. 3. Resultados. 4. Discusión. 5. Referencias bibliográfícas.

\footnotetext{
${ }^{1}$ Universidad de Alicante (España) anarosser@ua.es

${ }^{2}$ Universidad de Comillas (España) a.berastegui@comillas.edu
} 
Cómo citar: Rosser Limiñana, Ana; Berástegui Pedro-viejo, Ana (2017). "Retos y dificultades de la adopción abierta en España. El papel de la mediación”, en Mediaciones Sociales, 16, 175-191.

\section{Introducción}

\subsection{La adopción abierta y su implantación en España}

La reciente entrada en vigor en España de la Ley 26/2015 de Protección a la infancia y la adolescencia incluye entre sus innovaciones el reconocimiento de la adopción abierta, medida que permite al adoptado mantener relación con su familia de origen a través de vistas o comunicaciones, y abre la puerta a su implantación en España.

La naturaleza del contacto puede variar, desde un simple intercambio de información no reveladora de la identidad de las personas involucradas adopciones llamadas, por algunos, semi-abiertas - hasta el contacto directo adopciones este caso, totalmente abiertas (ISS/CIR n ${ }^{\circ} 194,2015$ ).

La adopción abierta es una medida utilizada desde los años 90 en otros países como EE UU, Gran Bretaña, Alemania, Austria, Canadá o Nueva Zelanda, con una valoración en general positiva por parte de todos los implicados, adoptados, familias biológicas, familias adoptivas y mundo profesional (Avery, 1998; Berry, 1993; Brodzinsky, Schechter, y Marantz Henig 2011; Grotevan y McRoy, 1998; Grotevant et al, 2008; Grotevant, McRoy, Wrobel y Ayers-López, 2013; Sullivan, 2004).

Son numerosos los estudios que señalan las ventajas de la adopción abierta (Grotevant et al, 2008; Haas, 2015; Siegel, 2012). En concreto, el estudio de Grotevant el al. (2008) indicaba que las familias adoptivas con contacto informaron tener niveles más altos de satisfacción con sus acuerdos de apertura, experimentando sentimientos más positivos sobre la madre biológica y poseer más conocimiento real y personal sobre la madre biológica que las familias sin contacto. Muchos de los participantes que ya tenían contacto querían aumentarlo en el futuro, siendo apenas reseñable la presencia de participantes querían ver disminuir la intensidad del contacto.

Como señala Ferrandis (2013; p. 13),

"Entre otros factores que han propiciado esta evolución que nos ha traído a la posibilidad de la adopción abierta están: el reconocimiento del derecho la identidad y al conocimiento de los orígenes, el creciente respeto por las madres biológicas, la positiva influencia normalizadora de la adopción internacional, la preocupación de los adoptados por sus antecedentes médicos y genéticos, las experiencias de los adoptados en su búsqueda de información y comprensión de su historia, la búsqueda de medidas de protección estables para los niños distintas del acogimiento residencial, y la creciente demanda de niños adoptables en los países occidentales".

Si todos los aspectos reseñados por Ferrandis son importantes, sin duda, la reciente apertura experimentada en el ámbito de la adopción y el reconocimiento 
del derecho de los adoptados a conocer sus orígenes, plasmado incluso en las modificaciones normativas más recientes (Ley 26/2015 de protección a la infancia y la adolescencia), ha sido uno de los elementos impulsores del reconocimiento de la adopción abierta a nivel legal.

Sin embargo, el desarrollo de la adopción abierta en España choca con la existencia de una concepción tradicional de la familia como esfera privada y una práctica de la adopción en la que se mantiene un estricto respeto a la confidencialidad y a la ruptura de todos los vínculos de origen.

Ambos aspectos hacen que su desarrollo en España esté resultando lento y generar recelo y desconfianza en todos los agentes implicados.

Así quedaba reflejado en titulares como el que podíamos leer en el Diario El País del 30 de septiembre de 2014: "El CGPJ expresa "cautelas" sobre la introducción de la adopción abierta". Una lectura detenida del informe del Consejo General del Poder Judicial (CGPJ), del que han sido ponentes los vocales Enrique Lucas y Álvaro Cuesta (2014), muestra que, en opinión de sus autores, no existe un consenso sobre la idoneidad de esta clase de adopción, que cuenta con defensores y detractores. Estos autores señalan que "En definitiva, se trata de una opción que pudiera ser considerada, en principio y para determinados casos, una solución adecuada para el menor, en particular en el caso de adolescentes" (p.85). Por ello, recomiendan cautela en su implantación y una regulación más detallada que incorpore la previsión de que la adopción abierta solo se constituirá si fuere conveniente al superior interés del menor, así como la necesidad de los informes psicológicos anteriores y posteriores a su constitución (p.86).

Igualmente, esta medida que podría generar cierta incertidumbre en las familias acogedoras y adoptivas acerca de posibles dinámicas de competición entre las familias biológica y adoptiva y su efecto en la vinculación del menor con esta última (Berástegui, 2016; p. 149). En consecuencia, cobra interés determinar si estás dificultades y/o resistencias pueden afectar al desarrollo de la medida.

Mención aparte merece el rol del menor. El estudio realizado por Siegel (2012) exploraba las reacciones de los jóvenes que habían crecido en adopciones abiertas. Estos consideraban que los desafíos en las relaciones abiertas de adopción son oportunidades para desarrollar la identidad, aumentar la familia y procesar los sentimientos que genera la separación. Sin embargo, la opinión de los adoptados y acogidos y en España también está por explorar en nuestro contexto.

\subsection{La importancia de la mediación en los procesos de adopción abierta.}

En estos procesos, como señala Ledesma (2013), la mediación juega un papel muy importante tanto en la búsqueda activa de orígenes del adoptado adulto, como en el desarrollo de los contactos entre la familia biológica y la familia adoptiva durante la infancia del adoptado.

Cuando este proceso se inscribe en una adopción abierta, no hablamos de una búsqueda de orígenes como tal; no es necesario realizar una búsqueda porque los menores saben quiénes son sus familiares biológicos, los han conocido y saben dónde viven. Es un restablecimiento del contacto con aquellas personas que también han sido muy importantes en su vida. Pero sí es necesario planificar, si 
cabe, cualquier relación que el niño vaya a tener con su familia biológica una vez adoptado.

Según Katz (2015), la mediación se convierte así en un mecanismo para explorar cómo se van a relacionar las partes en el futuro, para definir las relaciones y trasformar las expectativas individuales en expectativas comunes, creando el entorno necesario para aliviar las emociones de los padres biológicos y adoptivos. Kedward, Luckock y Lawson (1999) señalan que la mediación ayudará tanto a los padres biológicos como a los adoptivos a tomar decisiones conjuntas sobre la naturaleza y el alcance de los contactos posteriores a la adopción

Para Ledesma (2013), el mediador debe ser el primer filtro en los procesos de contacto del adoptado con la familia biológica. En una primera fase, el mediador debe ayudar a valorar las motivaciones y expectativas del menor y su familia para iniciar este contacto. También es preferible que el contacto se realice a través de un proceso de mediación familiar, de modo que puedan ajustarse las expectativas de cada uno y concretar las condiciones sobre el acuerdo entre ellos.

No sólo hay que centrarse en la negociación de los contactos. Las adopciones abiertas son experiencias complejas en las que los participantes van a necesitar apoyo adicional durante todo el proceso para ayudarles a comprenderlo y hacer frente a los cambios en las estructuras y límites de la familia, abordar sus propios sentimientos y preocupaciones y establecer medios confiables de comunicación entre sí (Logan, 2010; Maynard, 2005; Siegel, 2012).

Con todo ello se abre un nuevo campo profesional para los mediadores y un nuevo reto profesional para diseñar el proceso de forma adecuada.

\subsection{Objetivos.}

El objetivo de este trabajo ha sido analizar la opinión de expertos del ámbito del acogimiento familiar y la adopción sobre las posibles dificultades del desarrollo de la adopción abierta en España y ahondar sobre los mecanismos más adecuados para su implantación entre los que la mediación juega un importante papel. Este análisis es la base para diseñar un estudio más detellado0 sobre las necesidades, obstáculos y oportunidades percibidos por los distintos agentes, en el proceso de implantación de la adopción abierta en España.

La investigación se ha realizado en el marco del proyecto de I+D+I "La apertura de la comunicación sobre adopción en España: en camino hacia la adopción abierta" (PSI2013-47197-C3-1-R) financiado por el Ministerio de Economía y Competitividad.

\section{Método}

\subsection{Participantes}

La selección se hizo de modo intencional, buscando que los participantes fueran informantes clave, vinculados a servicios públicos o privados dedicados a la protección a la infancia, y en particular a la adopción y el acogimiento familiar, y con una larga trayectoria profesional en dicho ámbito. 
Finalmente fueros 6 las personas que accedieron voluntariamente a ser entrevistadas. Sus perfiles se pueden ver en la Tabla 1.

Tabla 1. Perfiles de los entrevistados

\begin{tabular}{|c|l|c|}
\hline & Entrevistado/a & $\begin{array}{c}\text { Años de } \\
\text { experiencia }\end{array}$ \\
\hline E1 & $\begin{array}{l}\text { Responsable del área de adopción y acogimiento de una } \\
\text { comunidad autónoma. }\end{array}$ & 15 \\
\hline E2 & $\begin{array}{l}\text { Responsable de una entidad dedicada a la adopción a cargo del } \\
\text { Programa de apoyo post-adoptivo de la comunidad autónoma. }\end{array}$ & 27 \\
\hline E3 & $\begin{array}{l}\text { Responsable de entidad sin ánimo de lucro, consultoría en } \\
\text { temas de Infancia. }\end{array}$ & 20 \\
\hline E4 & $\begin{array}{l}\text { Responsable del Servicio de adopción del Ministerio de } \\
\text { Sanidad, Servicios sociales e Igualdad. }\end{array}$ & 36 \\
\hline E5 & $\begin{array}{l}\text { Profesional de un Servicio de Adopciones provincial. } \\
\text { E6 }\end{array}$ & $\begin{array}{l}\text { Profesional encargado del seguimiento de acogimientos } \\
\text { familiares }\end{array}$ \\
\hline
\end{tabular}

Fuente: Elaboración propia.

\subsection{Instrumento}

Entrevistas en profundidad a los 6 expertos en acogimiento y adopción. A lo largo de las entrevistas se les han planteado diferentes cuestiones relacionadas con el tema a las que los entrevistados podían contestar de forma abierta.

En concreto, se plantean cuestiones relacionadas con cinco aspectos: 1) conocimiento de la población en general sobre adopción abierta, 2) posibilidades de implantación en España, 3) ventajas e inconvenientes de la medida, 4) tipología de casos en los que ven más viable o difícil su desarrollo y 5) algunas garantías a tener en cuenta.

\subsection{Procedimiento}

El guion de la entrevista se elaboró mediante un procedimiento en dos fases principales.

En una primera fase se construyó un guion a partir de los resultados de investigaciones previas y sugerencias del equipo investigador. Posteriormente, para comprobar su adecuación, se aplicó la entrevista a dos miembros del equipo, tras lo cual se realizaron algunos ajustes. 
Tras contactar con los expertos y solicitar su colaboración, las entrevistas se realizaron presencialmente por miembros del equipo investigador en los lugares de trabajo de los entrevistados. Estas fueron registradas con grabadora digital, con el consentimiento de los entrevistados, y transcritas literalmente.

A lo largo de las entrevistas se plantearon diferentes cuestiones relacionadas con el tema a las que los entrevistados podían contestar de forma abierta.

En concreto, la entrevista se estructura alrededor de las siguientes cuestiones: 1) conocimiento de la población en general sobre la adopción abierta, 2) posibilidades de implantación en España, 3) ventajas e inconvenientes de la medida ,4) tipología de casos en los que ven más viable o difícil su desarrollo y 5) algunas garantías a tener en cuenta.

\subsection{Análisis de los datos.}

En el marco de una investigación descriptiva, se ha realizado un análisis temático de contenido de las entrevistas mantenidas.

El análisis de contenido categorial temático (Andreu, 2002; Vázquez, 1994) parte de datos textuales y consiste en ir descomponiendo el texto en unidades temáticas para, posteriormente, proceder a su agrupamiento en categorías donde se consideran las similitudes o semejanzas que existan entre éstas en función de criterios preestablecidos.

Las diferentes categorías se han establecido a partir de la revisión teórica y conceptual del objeto de estudio, la adopción abierta.

El recuento del número de veces que cada categoría o tema ha sido señalada nos ofrece una visión de qué temas considera la población entrevistada más o menos prioritarios. En este caso tipos o categorías de creencias y expectativas sobre la adopción abierta, sus características y la opinión que les merece su implementación en España.

La unidad de análisis fue el párrafo y la decisión sobre la inclusión en cada una de las categorías se realizó a partir de la codificación de 2 jueces.

$\mathrm{Su}$ desarrollo implicó 5 fases:

1) Escucha inicial y trascripción literal de las entrevistas

2) Codificación abierta de los textos trascritos, según las cuestiones previamente definidas.

3) Codificación categorial en las 5 dimensiones básicas.

4) Análisis de contenido categorial temático siguiendo las recomendaciones de Vázquez (1994).

5) Validación del análisis mediante la comparación de la codificación de dos jueces.

Los datos cuantitativos se acompañan en este trabajo de fragmentos de las entrevistas para ir ilustrando las diferentes cuestiones analizadas por los entrevistados. 


\section{Resultados}

En primer lugar, todos los expertos coinciden en señalar que la posibilidad de establecer adopciones abiertas es una medida deseable y bien recibida, aunque desconocida para las familias españolas y que genera confusión en las mismas sobre las repercusiones que puede tener en el acogimiento/adopción que tienen en la actualidad.

"La adopción abierta ha provocado dos mecanismos contrarios: alegría en los acogedores, lo cual también es muy revelador: " $A$ Ah! Entonces me pueden convertir mi acogimiento en una adopción abierta, (...). Y de pronto terror en los adoptantes: “¿Cómo, cómo, cómo?”, que a lo mejor dicen: "Oiga, ¿es verdad que al año que viene a lo mejor le ponen visitas a mi hijo?". Bueno, pues ha habido que... varias llamadas y varias consultas en ese sentido de aclarar a las familias esas cosas". (E1)

Incluso comparten la idea de que es un modelo poco conocido para los propios profesionales. Los modelos existentes proceden del mundo anglosajón que entraña grandes diferencias con nuestro sistema de protección a la infancia.

"Hoy por hoy no lo sabemos nadie. Ni los técnicos que nos hemos tenido que poner a estudiarla o sea que tenemos que aprender mucho..." (E1)

"Algunos de los ejemplos no nos sirven. A ver, la mayor parte de las adopciones abiertas son en el ámbito anglosajón y norteamericano, donde son adopciones por libre consentimiento, donde la adopción aún se acuerda entre particulares, donde en el fondo es una variante de la maternidad subrogada..." (E1).

En este sentido es muy importante atender a la dimensión cultural y nacional a la hora de planificar e implantar la adopción abierta como ya señalaban Ryan et al, (2001) o Di Lisi (2015).

En consecuencia, y atendiendo a la segunda cuestión (Tabla 2), existe unanimidad en considerar que su implantación va a ser complicada. Entre las condiciones para una óptima implementación destaca que va a precisar que se dote a las familias de una información adecuada, tanto a las adoptivas como a las biológicas.

"Va a tocar una labor de información, pero básicamente de formación para las familias, las unas y las otras ¿eh?, que es que tampoco va a ser fácil para las familias biológicas pensarse en ver o tener algún tipo de contacto con quiénes crían a mis hijos..." (E2).

También se considera primordial que se forme a los profesionales, tanto del ámbito psicosocial como del judicial, para conocer las posibilidades y adecuación de la medida y así proponerla cuando sea conveniente al interés superior del menor. Llama la atención que los entrevistados esperan que se produzca cierta resistencia en los profesionales: 
"Lo importante no es solamente lo, qué piensan las familias, iy los profesionales? porque la propuesta tiene que surgir de los profesionales. Si los profesionales no creen en el recurso...." (E4).

"Las principales dificultades...? Aparte del miedo de las familias, pues ... flexibilizar la administración. Tanto a nivel administrativo como un poco las mentalidades de los técnicos, que a veces nos acogemos mucho a nuestro modelo y...nos cuesta un poquito... un poquito salir" (E6).

Por el contrario, la literatura internacional muestra mayores resistencias entre las familias que entre el mundo técnico a la hora de promover la apertura (Ryan et al, 2011)

Destaca entre los temas tratados la necesidad de mediar profesionalmente en estos procesos y acompañar y apoyar a las familias, tanto a las adoptivas como a las biológicas, antes, durante y después de los contactos, para que la medida funcione. Antes, ajustando expectativas, preparando el encuentro y estableciendo acuerdos sobre cómo realizarlos; mediando en los contactos, y apoyando ante las reacciones posteriores a todos los protagonistas, a la familia biológica, a la adoptiva y al propio menor. 
Tabla 2. Implantación de la adopción abierta en España.

\begin{tabular}{|c|c|c|}
\hline Categoría & Subcategorías & $\mathrm{n}$ \\
\hline \multirow{2}{*}{ Implantación en España } & Difícil, complicada & 6 \\
\hline & Sencilla & 0 \\
\hline \multirow{9}{*}{ Condiciones óptimas para su implantación } & $\begin{array}{l}\text { Requiere de formación de los } \\
\text { profesionales }\end{array}$ & 4 \\
\hline & $\begin{array}{l}\text { Requiere de un seguimiento/apoyo } \\
\text { técnico a las familias adoptivas y } \\
\text { biológicas. }\end{array}$ & 4 \\
\hline & $\begin{array}{l}\text { Requiere de un trabajo de } \\
\text { preparación con las familias } \\
\text { biológicas y adoptivas. }\end{array}$ & 3 \\
\hline & $\begin{array}{l}\text { Requiere de una preparación y } \\
\text { apoyo al menor }\end{array}$ & 1 \\
\hline & $\begin{array}{l}\text { Requiere de labor previa } \\
\text { información y formación a las } \\
\text { familias }\end{array}$ & 4 \\
\hline & $\begin{array}{l}\text { Hay que definir claramente los } \\
\text { supuestos } \\
\text { acuerdos. }\end{array}$ & 3 \\
\hline & Requiere de una necesaria & 2 \\
\hline & $\begin{array}{l}\text { No se pueden copiar los modelos de } \\
\text { otros países }\end{array}$ & 3 \\
\hline & $\begin{array}{l}\text { Requiere el establecimiento de } \\
\text { contactos mediados. }\end{array}$ & 3 \\
\hline
\end{tabular}

Fuente: Elaboración propia.

Para ello se precisa profesionales formados en mediación tal y como propuso Maynard (2005). La literatura internacional ha destacado la importancia de recibir apoyo y formación antes, durante y después del comienzo de la adopción para promover el contacto y cómo la adopción abierta es más exitosa en la medida que las familias han podido controlar y negociar el contacto y mantener esta mediación a lo largo de toda la vida (Crea y Barth, 2009).

En tercer lugar, al tratar sobre las ventajas e inconvenientes de la adopción abierta (Tabla 3), los expertos encuentran ventajas, especialmente como forma de dar seguridad jurídica a determinadas situaciones que se están dando de hecho, y en acogimientos permanentes. 
Desde el punto de vista del menor, se señala que esta fórmula permite dar una respuesta más adecuada a determinados casos:

"Es una alternativa y como tal cuantos más recursos tengamos para la enorme variedad, cuanto más haya mejor. Porque trabajando en infancia ¿sabes? hay tantas situaciones diferentes, con necesidades diferentes..." (E4).

Y que también reduciría el posible conflicto de lealtades del menor con las familias adoptiva y biológica.

"Es como una secuencia más natural de la vida, digo, "Aquella familia me tuvo, pero no me pudo criar, yo para vivir he necesitado dos familias, esta es la que me cría todos los días, la que... con la que vivo”. De alguna manera tener permiso oficial ¿no?, no porque esté firmado en un papel, sino que esta familia acepta esta otra familia, y esta familia mía con la que yo vivo ahora acepta a los míos, a la larga tiene que ser beneficioso ¿no?” (E2).

En este sentido, la estabilidad de la adopción como medida jurídica, frente al acogimiento familiar, ayuda a clarificar el papel de la familia biológica en la vida del niño y a genera vínculos con mayor seguridad, cuando pervive el contacto (Crea y Barth, 2009).

Se señala también que la adopción abierta daría continuidad al relato familiar, y reduciría la existencia de "secretos" o información ocultada deliberadamente al menor por la familia adoptiva (Tabla 3).

"Ellos tienen dos familias pertenecen a dos familias y cuánto más sepan de las dos familias mejor les va a ir en la vida (...) No necesitas ocultar nada, ni temer nada, ni comerte ya ningún fantasma sino bueno ésta es tu familia biológica, ésta es tu familia adoptiva, ésta es tu realidad, tienes dos familias. Eh... y puedes crecer desde eso y además la actitud de ambas familias, no hay... no hay secretos, son parte de la... de una misma realidad" (E3).

Sólo uno de los entrevistados consideraba que sería viable en España como un acuerdo desde el inicio de la formalización de la adopción como plantea la legislación vigente. Así, para los expertos consultados se considera más una estabilización del acogimiento familiar permanente sin retorno previsible y pocos lo consideran una medida a tomar "de inicio". 
Tabla 3. Ventajas e inconvenientes de la medida

\begin{tabular}{|l|l|l}
\hline Categoría & Subcategorías & n \\
\hline \multirow{5}{*}{ Ventajas de la medida } & $\begin{array}{l}\text { Da seguridad jurídica y estabilidad a situaciones } \\
\text { existentes (acogimientos permanentes, situaciones } \\
\text { de hecho }\end{array}$ & 4 \\
\cline { 2 - 2 } & $\begin{array}{l}\text { Es una transición más natural, más normalización } \\
\text { del proceso }\end{array}$ & 3 \\
\cline { 2 - 2 } Inconvenientes de la medida & $\begin{array}{l}\text { Mayor posibilidad de adaptarse a las necesidades } \\
\text { del caso }\end{array}$ & 2 \\
\cline { 1 - 2 } & $\begin{array}{l}\text { Viable desde el comienzo de la relación con la } \\
\text { familia adoptiva }\end{array}$ & 1 \\
\cline { 2 - 3 } & $\begin{array}{l}\text { Miedo en los padres adoptivos a que el menor padres adoptivos a que se decida que } \\
\text { quiera volver con su familia biológica }\end{array}$ & 4 \\
\cline { 2 - 3 } & $\begin{array}{l}\text { Salto cultural y de valores, disparidad de criterios } \\
\text { entre as familias }\end{array}$ & 2 \\
\hline
\end{tabular}

Fuente: Elaboración propia.

En cuanto a los inconvenientes, destaca el miedo de las familias adoptivas a que el contacto con la familia biológica ponga en riesgo su unidad familiar. También las dificultades derivadas de los límites, la disparidad de criterios entre una familia y otra.

"Que se lleven al niño, que el niño quiera volver con su familia biológica y te deje, eh... que te vean como peor (...). La disparidad de criterios educativos, la disparidad de percepciones del niño, en que en un determinado momento el niño pueda... cuestionarte como madre o cuestionar tu papel en su vida, o... todos esos son los propios miedos que son humanos..." (E3).

Este es un miedo muy frecuente, que se ha considerado uno de los grandes "mitos" en contra de la adopción abierta (Brown, Ryan y Pushkal, 2007) y contrarrestada por los datos de la investigación precedentes, aunque siempre desde el contexto anglosajón (Siegel, 2013).

Al reflexionar sobre cuáles serían los casos más adecuados para una adopción abierta, (Tabla 4), en la mirada de todos los entrevistados están los acogimientos permanentes, pensando que la medida de adopción abierta daría más consistencia a su situación. 
"En la mayor parte yo creo que la adopción abierta será una manera de dar seguridad y solidez a un acogimiento prolongado, donde es verdad que no habrá visos de reincorporación familiar, pero conviene mantener una relación simbólica por lo que suponga a la identidad del niño, al conocimiento de sus raíces, a no fantasear" (E1).

Para estos niños, la adopción abierta puede suponer una medida estable que, al mismo tiempo, minimiza la pérdida del niño, asegurándoles que podrán mantener el contacto cuando esto sea importante para ellos, facilitando la transición a la nueva situación y minimizando el miedo a la pérdida (Faulkner y Madden, 2012) Se contempla como una medida adecuada (y más aceptada por las familias adoptivas) para mantener el contacto con hermanos.

"La verdad es que las familias adoptivas, el que contacten con hermanos lo ven positivo. Y ahí sí que estarían mayoritariamente de acuerdo. Eso de no separar a hermanos, o si están separados facilitar encuentro. Yo creo que ahí, el tema de los hermanos, llega. El problema se plantea en el tema de los padres" (E5).

Así mismo la mayoría considera-que los casos más frecuentes serán aquellos en los que sólo se establezca un contacto indirecto, mediado por la entidad pública, mediante el trasvase de información, cartas, fotos, mensajes, etc., y de manera muy excepcional, permitiendo esta modalidad como forma de facilitar la adopción desde su resolución. La enorme variedad de grados de contacto también ha sido una variable contemplada en la investigación precedente (Wolfgram, 2008), de manera que el debate en el escenario internacional ha virado desde si el contacto es bueno o malo a cuestiones más específicas como qué tipo y tiempos del contacto son más recomendables para cada caso específico (McRoy et al., 2007)

Por otra parte, los expertos consideran, que no es una medida adecuada para todos los casos. Sobre todo, consideran que sería más difícil que las familias adoptivas den su consentimiento en casos en los que se ha dado en la familia de origen maltrato, negligencia severa y/o abuso ya que las familias han causado daño a los niños. Sin embargo, sería más viable en casos de imposibilidad de cuidado por discapacidad física o mental, por falta de recursos, o en caso de embarazos adolescentes. En casos de enfermedad mental, y también en casos de drogodependencias, todos los expertos señalan que dependería de la problemática presente en cada caso en particular aunque tienden a considerarlos casos no adecuados para una adopción abierta. También se plantean dificultades cuando la familia de origen pertenece a una cultura o etnia distinta a la de la familia biológica, porque suponen un salto cultural y de valores mayor. 
Tabla 4. Procedimientos y perfiles de menores

\begin{tabular}{|l|l|l|}
\hline Categoría & Subcategorías & $\mathrm{n}$ \\
\hline \multirow{5}{*}{ Procedimiento y perfiles } & Adecuado para acogimientos prolongados & 4 \\
\cline { 2 - 3 } & Adecuado para niños un poco mayores & 2 \\
\cline { 2 - 3 } & Adecuado entre hermanos & 2 \\
\cline { 2 - 3 } Casos más difíciles de aceptar & $\begin{array}{l}\text { Más probable contactos indirectos: cartas, fotos, } \\
\text { mensajes, etc. }\end{array}$ & 3 \\
\hline & Enfermedad mental & 5 \\
\cline { 2 - 3 } & Toxicomanías & 5 \\
\cline { 2 - 3 } & Falos tratos, abusos, negligencias graves & 5 \\
\hline & Familias desestructuradas & 1 \\
\hline & Diferencias culturales con familia biológica & 1 \\
\hline
\end{tabular}

Fuente: Elaboración propia.

En cualquier caso, las decisiones deberían tomarse caso por caso (Von Korff et al., 2008) ya que por el momento se carece de guías estandarizadas para la toma de decisiones; $\mathrm{y}$ también de un cuerpo formado de profesionales formados para estos casos (Brown et al., 2007)

En relación con el último punto, destaca la llamada que hacen los expertos a la necesidad de dotar de garantías al procedimiento, mediante la información, preparación y apoyo a las familias tanto biológica como adoptiva y al propio menor por profesionales especialmente formados, del seguimiento de los casos, para poder plantear modificaciones a la medida si el caso lo requiere, a la regulación de las vías de contacto, la mediación entre las partes para establecer acuerdos sobre el cómo, el cuándo, etc. de esos encuentros, y poder contar con Puntos de encuentro para la supervisión de los contactos directos.

“Ojalá no necesitemos también 15 años de equivocaciones como hemos tenido en el acogimiento para hacer bien las adopciones abiertas porque son realidades psicológica y socialmente tan complejas...!" (E1).

\section{Discusión y conclusiones}

Este trabajo es una primera aproximación al estado de la cuestión sobre la implantación de la adopción abierta en España, recientemente legislada, lo cual explica que sólo se recojan los testimonios de un pequeño grupo de profesionales, 
aunque todos ellos con amplia trayectoria en el ámbito de la adopción y el acogimiento familiar.

El primer dato a destacar es que la inclusión de la adopción abierta en la reglamentación jurídica de las medidas de protección a la infancia y la adolescencia en España ha sido bien recibida por parte de los expertos encuestados.

Todos reconocen que la adopción abierta abre nuevas posibilidades en la intervención y permite adecuar las medidas de protección a las necesidades de algunos menores sobre los que no es viable el retorno con la familia de origen pero que mantienen ciertos vínculos con alguno de sus miembros que no está justificado interrumpir. Sin duda, esta casuística se aleja bastante del modelo americano en el que, a menudo, son las familias biológicas las que seleccionan a las familias adoptivas de sus hijos y deciden si desean mantener cierto contacto con aquellos, lo que confiere a la implantación de la adopción abierta en España un carácter diferente, más acorde a la cultura existente sobre la familia en general y sobre la adopción en particular.

Aunque la adopción abierta puede ofrecer ventajas al niño, como una cierta forma de continuidad o un sentimiento más fuerte de identidad, también puede presentar riesgos y no puede recomendarse en cualquier situación (SSI/CIR, 2015). Para este organismo,

"la adopción abierta es una opción permanente de acogimiento de tipo familiar que puede ser considerada para ciertos perfiles de niños, con la condición de que se establezcan las garantías indispensables para su buen funcionamiento, como su incorporación a un marco jurídico, su supervisión por una autoridad competente, una preparación exhaustiva $\mathrm{y}$ un acompañamiento profesional continuo de las partes involucradas" (p.2).

Los expertos entrevistados para este trabajo coinciden con estas recomendaciones. Así mismo, coinciden en que su implantación es positiva siempre y cuando se establezcan las garantías indispensables para su buen funcionamiento, como la preparación y el apoyo a las familias y el menor a lo largo de todo el proceso a cargo de profesionales especialmente capacitados.

Los resultados, sin embargo, ponen de manifiesto también la complejidad que entraña la medida que, para resultar beneficiosa, va a requerir que los contactos se realicen de manera acordada, mediada y progresiva, atendiendo al superior interés del niño como consideración primordial, y en segundo lugar, al respeto y consideración de las familias.

Para ello, entre los factores a tener en cuenta para mejorar los contactos destacamos la preparación previa de las familias (Ryan et al., 2011), la participación de los profesionales para ayudar a comprender lo que supone la adopción abierta $\mathrm{y}$, especialmente, los detalles acordados para su desarrollo y los compromisos que implica (Maynard, 2005), y que la vía para llegar a estos acuerdos sea la mediación (Maynard, 2005). La mediación supone, en este sentido, una alternativa a los procedimientos judicializados y adversariales, cuando se busca la colaboración de todos los miembros del triángulo adoptivo en el trabajo a favor del superior interés del niño. La mediación tiene un enorme campo de aplicaciones en las medidas de protección infantil para resolver conflictos entre las familias, los 
profesionales y otros implicados, tratando de poner el bienestar el niño en el centro y se ha usado con éxito en la promoción de la adopción abierta desde los años 80 y se está implantando como un medio recomendable para hacer la búsqueda de los orígenes también en nuestro país (Ledesma, 2013).

En conclusión, el marco de intervención más adecuado en la adopción abierta es la mediación y es necesaria la presencia de los mediadores, cualificados en el tema de la adopción y neutrales con respecto a las familias, en los equipos que intervienen en los procesos de adopción. Todo ello debería ser tenido en cuenta en el desarrollo reglamentario de la medida y en la formación de los profesionales.

Sin duda, la implantación de la adopción abierta entraña oportunidades y desafíos para todos sus protagonistas (Siegel, 2012). Y también para las administraciones a la hora de implantarla. Es necesario, como señala Berástegui (2016; p. 148), que todos los agentes implicados en la protección de menores (técnicos, familias, activistas, investigadores, menores y adultos adoptados y acogidos) definan los parámetros básicos de la adopción abierta en nuestro sistema de protección en los próximos años.

\section{Referencias bibliográficas}

Andréu, J. (2002). Las técnicas de análisis de contenido: una revisión actualizada. Fundación Centro Estudios Andaluces, Universidad de Granada, 10(2), p. $1-34$.

Avery, R.J. (1998). Information Disclosure and Openness in Adoption: State Policy and Empirical Evidence. Children and Youth Services Review, 20 ( 1/2), 57-85.

Berástegui, A. (2016). La adopción abierta: de las creencias y los datos. en R. Arce, B. G. Amado, M. Vilariño, IX Congreso Internacional de Psicología Jurídica y Forense. Libro de Actas, págs. 148-150, Sociedad Española de Psicología Jurídica y Forense, Santiago de Compostela (La Coruña).

Berry, M. (1993) Adoptive parents' perceptions of, and comfort with, open adoption. Child Welfare: Journal of Policy, Practice and Program, 72(3), pp. 231-253.

Brodzinsky, D.M., Schechter, M. y Marantz Henig, R. (2011). Soy adoptado. La vivencia de la adopción a lo largo de la vida (Nueva edición revisada y actualizada). Madrid: Grupo 5.

Brown, D., Ryan, S., y Pushkal, J.T. (2007). Initial validation of the Open Adoption Scale: Measuring the influence of adoption myths on attitudes toward open adoption. Adoption Quarterly, 10(3-4), 179-196.

Consejo General del Poder Judicial (2014). Informe al Anteproyecto de Ley de Protección a la Infancia. Disponible en: http://www.poderjudicial.es/cgpj/es/Poder-Judicial/ConsejoGeneral-del-Poder-Judicial/Actividad-del-CGPJ/Informes/Informe-al-Anteproyecto-deLey-de-Proteccion-a-la-Infancia

Crea, T. M. y Barth, R. P. (2009). Patterns and predictors of adoption openness and contact: 14 years postadoption. Family Relations, 58(5), 607-620. 
Faulkner, M., y Madden, E.E. (2012). Open adoption and post-adoption birth family contact: A comparison of non-relative foster and private adoptions. Adoption Quarterly, 15(1), 35-56.

Grotevant, H.D. y Mcroy, R.G. (1998). Openness in Adoption: Exploring Family Connections. California: Sage Publications, pp. 2-6.

Grotevant, H.D., Wrobel, G.M., Von Korff, L., Skinner, B., Newell, J., Friese, S. y Mcroy, R.G. (2008). Adoption Quaterly, 10(3 \&amp; 4), 79-101.

Grotevant, H.D., Mcroy, R.G., Wrobel, G.M. y Ayers-López, S. (2013). Contact Between Adoptive and Birth Families: Perspectives from the Minnesota Texas Adoption Research Project. Child Developement Perspectives, 7(3), 193-198.

Haas, B. (2015). Treinta años de experiencia en la adopción abierta: Ventajas, obstáculos y conocimientos profesionales expertos. Boletín SSI/CIR, 194, 6-7.

Katz, J.M. (2015). La mediación en la fase preadoptiva: Una amplia variedad de beneficios para todas las partes, considerando la adopción abierta. Boletín SSI/CIR, 194, 8-9.

Kedward, C., Luckock, B. y Lawson, H. (1999). Mediation and post-adoption contact: the early experience of the Post-Adoption Centre Contact Mediation Service. Adoption \& Fostering Journal, 23(3), 16-26.

Di Lisi, S. (2015). Holden Lori with Hass Crystal: The open-hearted way to opten adoption. Helping your child growing up whole. Journal of Child and Family Studies, 24 (5), 1519-1522.

Ledesma, J. (2013). La mediación familiar en la búsqueda de orígenes. Revista Digital Mundo Mediación, 3. Disponible en: http://www.mundomediacion.es/revista-11edicion-8/3-vivir-la-mediacion/27-la-mediacion-familiar-en-la-busqueda-de-origenes

Ley 26/2015 de protección a la infancia y la adolescencia. BOE n 180, de 29 de julio de 2015. Disponible en: https://www.boe.es/buscar/act.php?id=BOE-A-2015-8470

Logan, J. (2010). Preparation and planning for face-to-face contact after adoption: the experience of adoptive parents in a UK study. Child \&family social work, 15(3), 315324.

Maynard, J. (2005). Permanency mediation: a path to open adoption for children in out-ofhome care. Child welfare, 84(4), 507-526.

Mcroy, R. G., Grotevant, H. D., Ayers-Lopez, S. y Henney, S. (2007). Open adoptions: Longitudinal outcomes for the adoption triad. Handbook of adoption: Implications for researchers, practitioners, and families, 175-189.

Ryan, S.D., Harris, G., Brown, D., Houston, D.M., Smith, S.L. y Howard, J.A. (2011). Open adoptions in child welfare: Social worker and foster/adoptive parent attitudes. Journal of public child welfare, 5(4), 445-446. 
Siegel, D. H. (2012). Growing up in open adoption: Young adults' perspectives. Families in Society: The Journal of Contemporary Social Services, 93, 133-140.

Siegel, D. H. (2013). Open adoption: Adoptive parents' reactions two decades later. Social work, 58(1), 43-52.

SSI/CIR (2015). La adopción abierta: Varias velocidades, varias medidas. Centro Internacional de referencia para los derechos del niño privado de la familia, 194. Disponible en www.iss-ssi.org

Sullivan, R. y Lathrop, E. (2004). Openness in adoption: retrospective lessons and prospective choices. Children and Youth Services Review, 26, 393-411.

Vázquez Sito, F. (1994). Análisis de contenido categorial: el análisis temático. Barcelona: Unitat de Psicologia Social -Universitat Autònoma de Barcelona.

Von Korff, L., Grotevant, H. D., y Mcroy, R.G. (2006). Openness arrangements and psychological adjustment in adolescent adoptees. Journal of Family Psychology, 20(3), 531.

Wolfgram, S. M. (2008). Openness in adoption: What we know so far-A critical review of the literature. Social Work, 53, 133-142. 